\title{
Mechanism of dicarbonyl(2,4-pentanedionato)iridium(I) decomposition on iron surface and in gas phase: complex experimental and theoretical study
}

Evgenia A. Kovaleva ${ }^{1,2^{*}}$, Alexander A. Kuzubov¹, Evgeniia S. Vikulova ${ }^{2}$, Tamara V. Basova ${ }^{2,3}$, Natalya B. Morozova ${ }^{2}$

1Siberian Federal University, 79 Svobodny pr., Krasnoyarsk, 660041, Russian Federation

${ }^{2}$ Nikolaev Institute of Inorganic Chemistry, SB RAS, 3 Academika Lavrentieva pr., 630090, Novosibirsk, Russian Federation

${ }^{3}$ Novosibirsk State University, 2 Pirogova Str., 630090, Novosibirsk, Russian Federation

\begin{abstract}
The mechanism of thermal destruction of $\operatorname{Ir}(\mathrm{acac})(\mathrm{CO})_{2}$ as one of the most important MOCVD precursors for Ir coatings deposition was proposed on the footing of the in situ mass spectrometry analysis and quantum chemical modeling. Calculated structural parameters and vibrational spectra of $\operatorname{Ir}($ acac $)(\mathrm{CO})_{2}$ molecule were found to be in a fairly good agreement with the experimental data. $\operatorname{Ir}($ acac $)(\mathrm{CO})_{2}$ was found to unlikely decompose in the gaseous phase while its adsorption onto the iron surface leads to major structural distortions easing the bond cleavage, molecule decomposition with subsequent formation of iridium films.
\end{abstract}

Keywords: iridium films, MOCVD, $\operatorname{Ir}($ acac $)(\mathrm{CO})_{2}$, thermal decomposition, mass spectrometry, quantum chemical modeling

\section{Introduction}

Iridium-containing film materials have a number of topical applications, e.g. oxidant-resistant refractory coatings for aerospace devices [1], electrochemical biocompatible layers for cardio- and neurosurgery electrodes [2-5]. These materials could be obtained using different techniques, namely, electrodeposition [6,7], magnetron sputtering [8-10], Metal Organic Chemical Vapor Deposition (MOCVD) $[11,12]$, and some others. The latter method is recognized to be one of the most 
promising ones since it combines the possibility of uniform coverage for complex shape substrates, precious multiparameter monitoring permitting to control characteristics of the deposited coating including variation of its composition and structure, and high ratio of precursor utilization [11,12].

Thermochemical parameters of initial volatile compounds (precursors) play a key role in the development of processes of deposition from the gaseous phase. To be effectively used in MOCVD process, the precursor must possess sufficient vapor pressure values (volatility), high stability in the evaporation temperature range, complete decomposition at substrate (deposition) temperatures and some other characteristics. Knowledge of a precursor vapor thermolysis mechanism is essential for the evaluation of coating composition and optimization of the MOCVD conditions. Currently, there are only few methods for experimental investigation of thermal destruction processes on the heated surface (substrate), such as in situ high temperature mass spectrometry [13-16] and in situ infrared absorption spectroscopy [17-19]. However, they are unique and quite inaccessible due to the requirement of special equipment and complexity of data interpretation. Thus, quantum chemical modeling of these processes seems to be more efficient tool for their investigation.

Thus, the present paper describes the first attempt of thermal destruction modeling for iridium precursor vapors. To date, a wide number of iridium complexes with B-diketones and their derivatives, cyclopentadienyls, alkenes, carbonyls, phosphines and other ligands have been proposed as MOCVD precursors [11,12 and references therein, 20-23]. Nevertheless, the investigations of vapor thermal destruction on the heated surface have only been carried out for $\operatorname{Ir}(\mathrm{acac})_{3}$ (acac $=$ acetylacetonato) [24,25], Ir(cod) (acac) $(\operatorname{cod}=$ cyclooctadiene-1,5) [26], $\operatorname{Ir}(\operatorname{cod})(\mathrm{MeCp})$ $(\mathrm{MeCp}=$ methylcyclopentadienyl $)$ [26] and $\operatorname{Ir}(\mathrm{acac})(\mathrm{CO})_{2}$ [24,27] complexes. Among them, $\operatorname{Ir}($ acac $)(\mathrm{CO})_{2}$ is characterized by the highest volatility (temperature dependence of saturated vapor pressure at $306-333 \mathrm{~K}: \lg (P$, Torr $)=12.6-$ $4910 /(T, K))$ [28] along with the lowest carbon content providing the purity of the obtained coatings and relatively low deposition temperatures, even at hydrogen atmosphere $\left(<350^{\circ} \mathrm{C}\right)$ [24,27]. These features make $\operatorname{Ir}($ acac $)(\mathrm{CO})_{2}$ promising MOCVD precursor. For this reason, this complex has been chosen as a subject of the present investigation in order to compare theoretical and experimental data. 


\section{Experimental procedure}

Synthesis of $\operatorname{Ir}(\mathrm{acac})(\mathrm{CO})_{2}$ precursor was carried out according to the procedure described previously in the literature [24] by bubbling carbon monoxide through $\operatorname{Ir}(\operatorname{cod})($ acac) solution in hexane in inert atmosphere. The product was purified by vacuum sublimation $\left(80^{\circ} \mathrm{C}, 5 \cdot 10^{-2} \mathrm{Torr}\right)$. Yield is $90 \%$. Anal. Calc. for $\mathrm{IrC}_{7} \mathrm{H}_{7} \mathrm{O}_{4}$ (mass. \%): C, 21.2; H, 2.0. Found (Model CARLO-ERBA-11008 elemental analyzer): C, 21.2; H, 2.1. Synthesis and detailed characterization of $\operatorname{Ir}(\mathrm{cod})$ (acac) are described in [29]. IR spectrum of $\operatorname{Ir}(\mathrm{acac})(\mathrm{CO})_{2}$ as a pellet in $\mathrm{KBr}$ was recorded using a Vertex 80 FTIR spectrometer (see Figure 1b). Raman spectrum of $\operatorname{Ir}\left(\right.$ acac) $(\mathrm{CO})_{2}$ powder (see Figure 1d) were recorded with a Triplemate SPEX spectrometer equipped with CCD detector in a back-scattering geometry. The 488 $\mathrm{nm}, 10 \mathrm{~mW}$ line of an Ar-laser was used for spectral excitation.
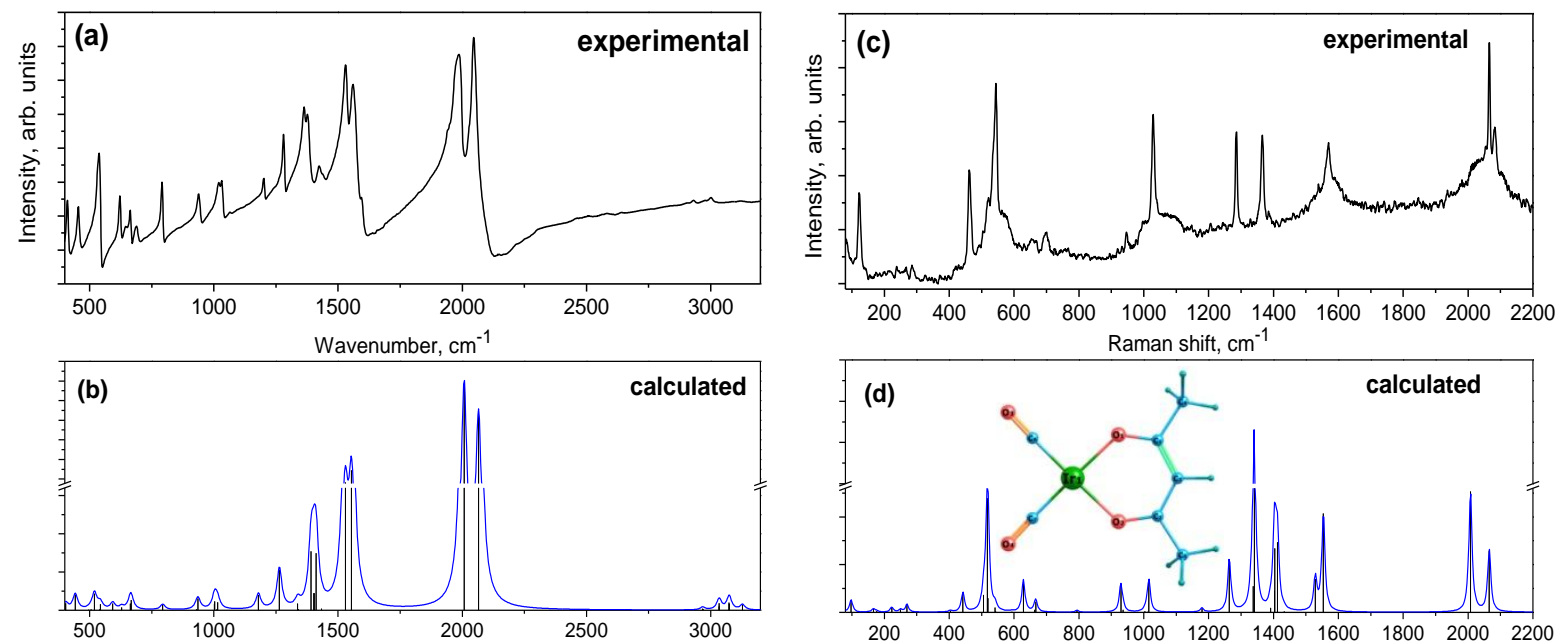

Figure 1. Calculated (a,c) and experimental (b,d) IR (a,b) and Raman (c,d) spectra for $\operatorname{Ir}(\mathrm{acac})(\mathrm{CO})_{2}$. The inset shows the structure of $\operatorname{Ir}(\mathrm{acac})(\mathrm{CO})_{2}$ molecule

Thermal decomposition of $\operatorname{Ir}(\mathrm{acac})(\mathrm{CO})_{2}$ complex was studied by the analysis of gas phase mass spectra temperature dependence (see Figure 2). The data regarding the ions presence in the reaction chamber give the important information about the chemical process. However, there are still some issues couldn't be explained since the experimental conditions of mass spectra detection themselves influence on the nature of the observed ions, namely, on the presence of radical 
particle $\mathrm{C}_{2} \mathrm{H}_{3} \mathrm{O}^{+}$etc. In addition, some of the reaction products cannot be seen in the spectra if they are adsorbed on the reactor's wall. These drawbacks of the experimental technique do not allow us to propose an unambiguous scheme of the reaction. Moreover, one can expect that the act of decomposition would take place rather on the reactor walls than in the gas phase. Seeking for the elucidation of these issues, we then performed density functional theory (DFT) simulation of the $\operatorname{Ir}($ acac $)(\mathrm{CO})_{2}$ decomposition in the gas phase and on the iron surface.

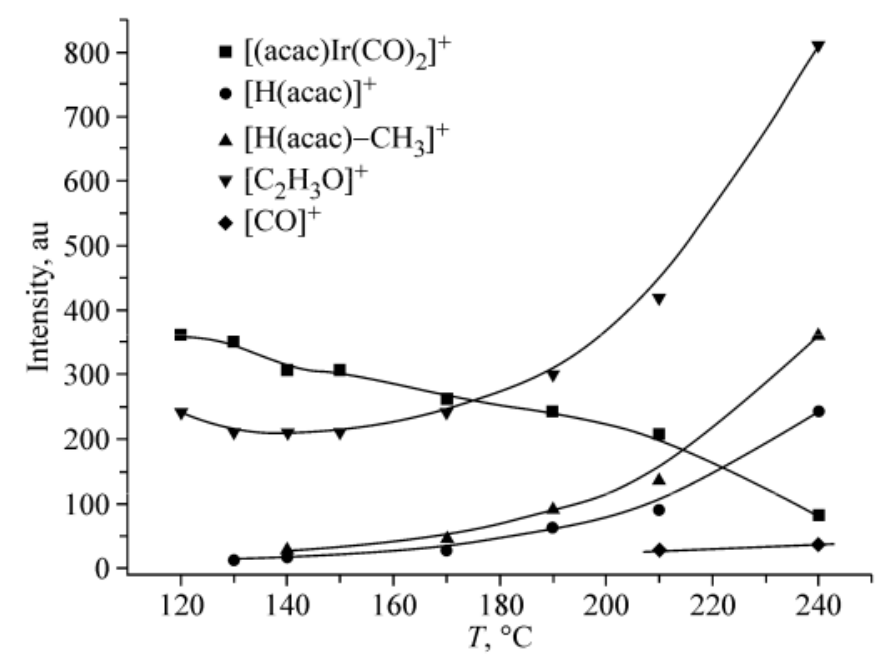

Figure 2. Intensities of ion peaks in mass spectra versus temperature during the $\operatorname{Ir}($ acac $)(\mathrm{CO})_{2}$ vacuum decomposition [24]

\section{Modeling and discussion}

\section{1 $\operatorname{Ir}($ acac $)(\mathrm{CO})_{2}$ single molecule decomposition}

Geometry optimization of $\operatorname{Ir}($ acac $)(\mathrm{CO})_{2}$ was carried out by means of density functional theory using BLYP exchange-correlation functional, def2-SVP and def2SVP/J (auxiliary) basis sets and effective core potentials for Ir atom using an ORCA quantum chemistry program package [30]. Optimization was performed until the energy difference between two steps was less than $10^{-4} \mathrm{eV}$, and root-mean squared energy gradient was less than $5 \cdot 10^{-3} \mathrm{eV} / \mathrm{A}$. A good agreement with crystallographic data [31] was reached (see Table S1, inset of Figure 1). Then IR and Raman spectra were calculated for the equilibrium geometry (Figure 1a, 1c) and compared with the experimentally measured spectra. Due to the symmetry of the molecule, all vibrational frequencies present both in IR and Raman spectra (see Table S2). The experimentally measured vibrational frequencies are in a fairly good agreement 
with the DFT theoretical predictions. The difference between the intensities of some calculated and experimental vibrations appears to be associated with systematic errors caused by a basis set incompleteness, neglect of electron correlation and vibrational anharmonicity [32]. Moreover, the calculations of the spectra have been done for one molecule in the gaseous phase without taking into account intermolecular interactions, whereas the experimental vibrational spectra have been measured for powders.

The analysis of vibrational modes and Mayer bond order allows suggesting Ir$\mathrm{O}$ bonds are broken at the first step of complex decomposition. This may proceed through the constant increase of $\mathrm{Ir}^{-} \mathrm{O}_{1}{ }^{-} \mathrm{C}$ angle from $128^{\circ}$ equilibrium value up to $220^{\circ}$ (which corresponds to the increase of $\mathrm{Ir}^{-} \mathrm{O}_{2}$ bond from 2.07 to $4.36 \AA$ (see Figure 3)). It is worth mentioning that there is no maximum observed in the energy path diagram but kind of a plateau is observed when $\mathrm{Ir}^{-} \mathrm{O}_{2}$ bond length increases. Thus, the Ir complex gas phase decomposition goes through a long-life metastable state instead of a conventional transition state. The geometry determined as the highest energy structure by transition state calculation is characterized by $\operatorname{Ir}^{-} \mathrm{O}_{1}-\mathrm{C}$ angle equal to $219^{\circ}$ and $\mathrm{Ir}^{-} \mathrm{O}_{2}$ bond length is equal to $4.20 \AA$ (Figure 3). The height of the potential barrier is then supposed to be $1.97 \mathrm{eV}$. However, according to the analysis of vibrational modes, there are no complex modes in its spectrum. This state is, hence, indeed not a transition but a metastable state. 


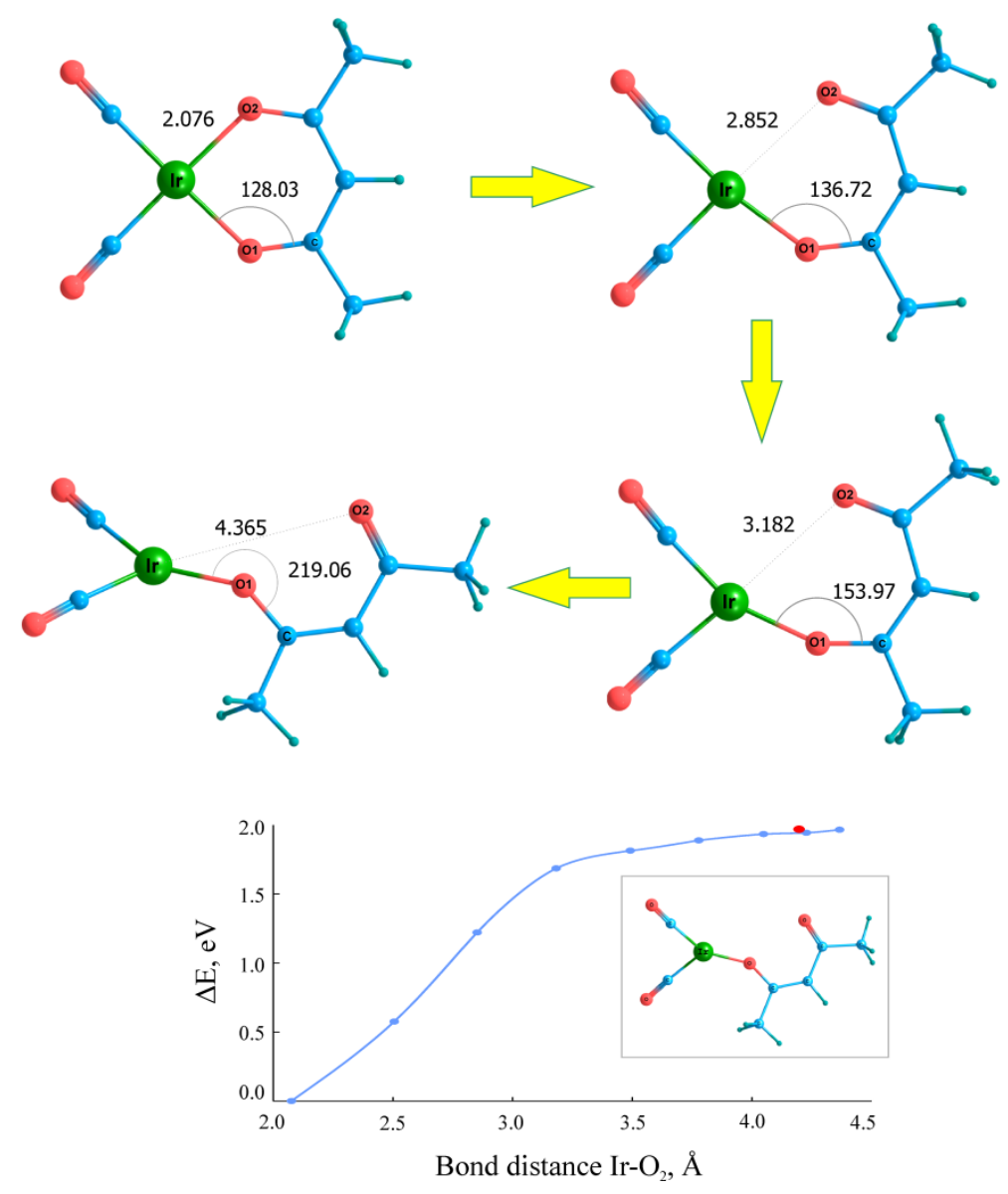

Figure 3. Scheme of $\operatorname{Ir}(\mathrm{acac})(\mathrm{CO})_{2}$ decomposition and corresponding energy path. Inset shows the structure of a metastable state denoted as a red dot on the energy diagram.

In order to prove the proposed mechanism, we also considered other possible ways of the molecule destruction: carbonyl group detachment, simultaneous cleavage of two Ir-O bonds, and breakaway of - $\mathrm{CH}$ - group hydrogen (see Figure 4). The barrier heights were estimated to be 2.99, 5.06 and $5.03 \mathrm{eV}$, respectively. Hence, the above mentioned reaction path is the most probable one among all.
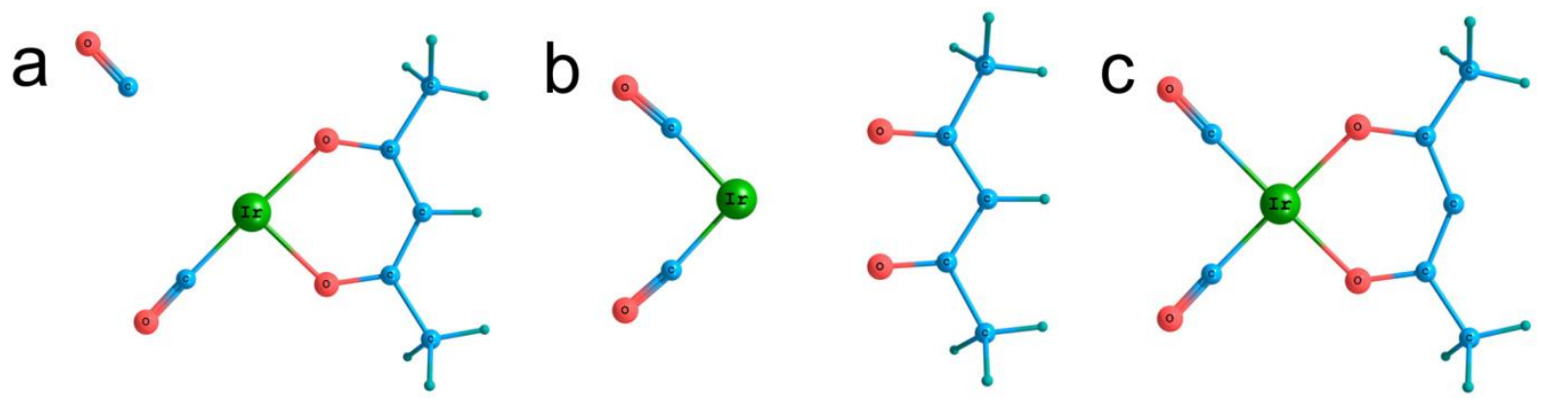

Figure 4. Possible mechanisms of $\operatorname{Ir}($ acac $)(\mathrm{CO})_{2}$ decomposition 
In the next step, we considered the possibility of $\mathrm{Ir}^{-} \mathrm{O}_{1}$ bond cleavage or $\mathrm{C}_{2} \mathrm{H}_{3} \mathrm{O}$ elimination. High energy barriers (2.62 and $2.73 \mathrm{eV}$, respectively) for the second stage, along with the above described metastable state, testify the low probability of gas phase decomposition of the Ir complex.

\subsection{Iron-supported $\operatorname{Ir}($ acac $)(\mathrm{CO})_{2}$ decomposition}

Keeping in mind the fact that experimentally observed decomposition most likely takes place not in vacuum but on the reactor walls made of stainless steel, we then investigated the influence of surface interactions on the decomposition process. For this purpose, we calculated the adsorption of $\operatorname{Ir}($ acac $)(\mathrm{CO})_{2}$ on a $\mathrm{Fe}(001)$ slab as a model surface. Periodic boundary conditions were used for the iron slab containing 8 atomic layers (which was found to be sufficient according to the preliminary tests). A supercell containing $5 \times 5$ surface unit cells was used for complex molecules being located distant from each other $(\sim 7.68 \AA$ between adjacent molecules). A vacuum interval of $\sim 10 \AA$ was set normal to the surface in order to exclude the artificial interactions between neighboring images. All calculations in periodic boundary conditions were performed using OpenMX program package using pseudoatomic orbitals and norm-conserving Vanderbilt pseudopotentials [33] within the GGA-PBE formalism [34,35]. The maximum force acting on atoms less than $0.01 \mathrm{eV} / \AA ̊$ was used as the stopping criterion for geometry optimization. Monkhorst-

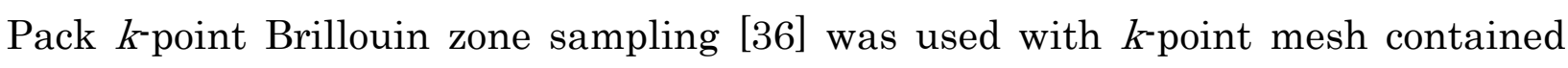
$2 \times 2 \times 1 \mathrm{k}$-points along $a, b$ and $c$. In order to check whether the results obtained by two different methods are compatible, we preliminary calculated the height of potential barrier for gas phase decomposition using OpenMX software with nudged elastic band (NEB) method [37,38] and found it equal to $1.95 \mathrm{eV}$, that is in perfect agreement with the previous result obtained using ORCA $(1.97 \mathrm{eV})$.

A strong structural distortion of the molecule took place during the geometry optimization (Figure 5). Ir-O and $\mathrm{Ir}^{-\mathrm{C}}$ bonds became significantly larger when adsorbed on the iron surface; carbonyl and methyl groups did not lie in the same plane anymore. Thus, the mechanism involved into the decomposition of $\operatorname{Ir}($ acac $)(\mathrm{CO})_{2}$ deposited on iron surface should be essentially different from that in the gas phase. 

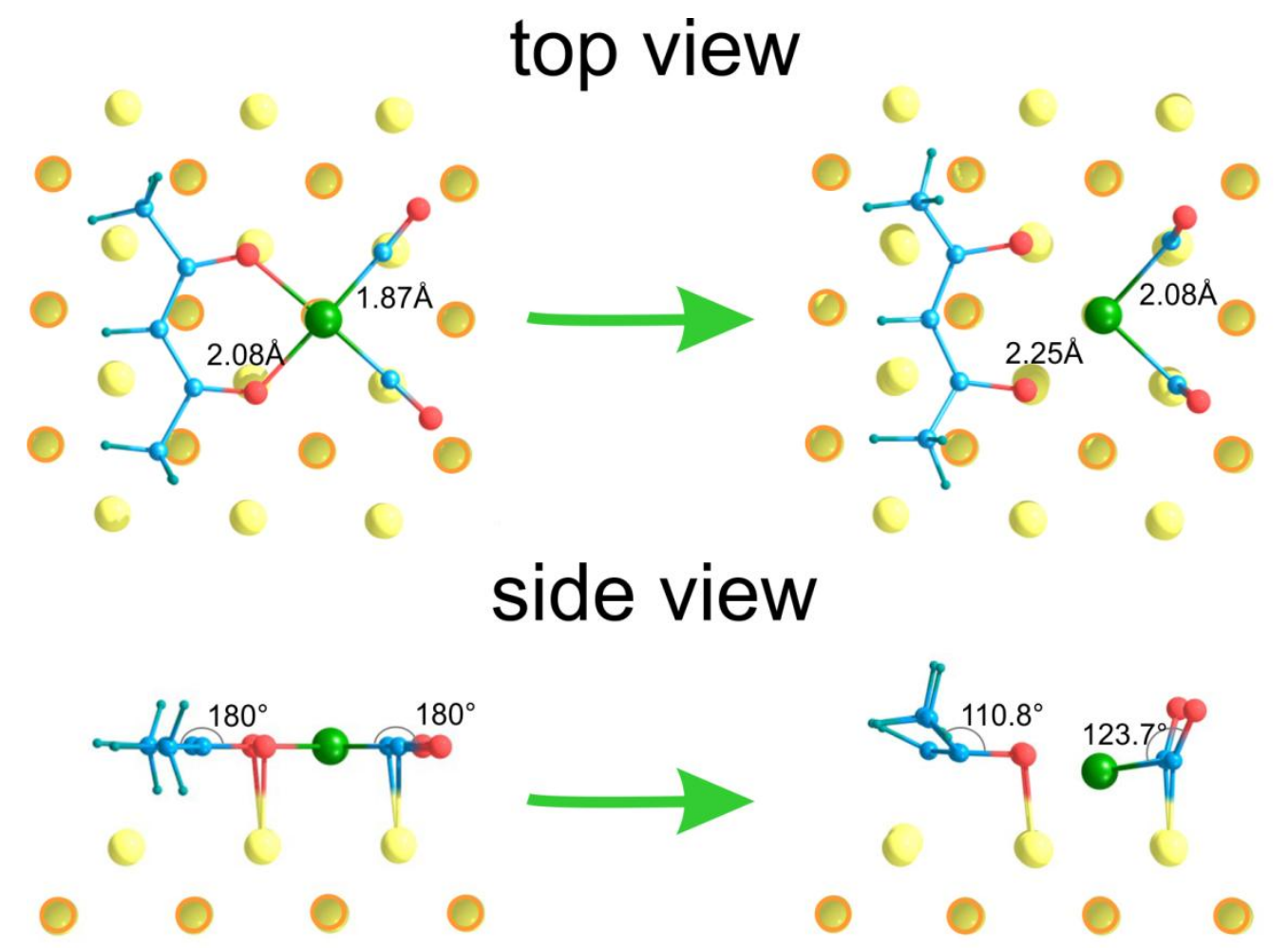

Figure 5. Structural distortion of $\operatorname{Ir}(\mathrm{acac})(\mathrm{CO})_{2}$ adsorbed on the Fe(001) surface

The analysis of molecular orbitals distribution for the optimized structure of $\operatorname{Ir}($ acac $)(\mathrm{CO})_{2}$ adsorbed on the iron surface was performed up to the HOMO-30 and showed that the bonding states of acac fragment with iron slab lie much lower in energy than the bonding states of $\mathrm{Fe}(001)$ and $\mathrm{CO}$ groups. In fact, HOMO-3 (-0.044 $\mathrm{eV})$ and HOMO-4 $(-0.055 \mathrm{eV})$ correspond to the antibonding states of $\mathrm{Fe}(001) / \mathrm{acac}$ fragment (see Figure 6) while the bonding states lie in the range of [-0.24:-0.15] eV. Corresponding bonding states for $\mathrm{CO}$ molecules and $\mathrm{Fe}(001)$ surface can be observed in the wide range from -0.22 to $-0.03 \mathrm{eV}$ (HOMO-1). This means that other acac fragment levels lie much lower than HOMO-30, testifying its stronger interaction with the substrate. Thus, it is reasonable to suppose that carbonyl groups eliminate first and then desorb from the surface, as observed in the experiment (see Figure 2).

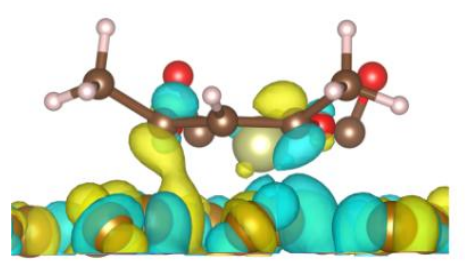

HOMO-25

$\mathrm{E}=-0.238 \mathrm{eV}$

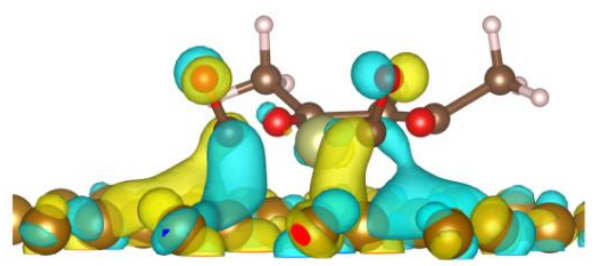

HOMO-17

$E=-0.133 \mathrm{eV}$

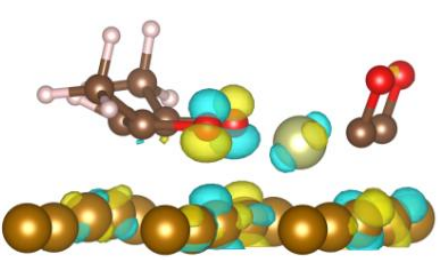

HOMO-3

$E=-0.044 \mathrm{eV}$

Figure 6. Molecular orbitals corresponding to the acac (HOMO-25) and CO (HOMO-

17) bonding with an iron slab, antibonding acac orbital (HOMO-3) 
Three paths of further $\operatorname{Ir}(\mathrm{acac})(\mathrm{CO})_{2}$ decomposition were modeled: (a) detachment of $\mathrm{CO}$ group followed by its adsorption somewhere on the iron surface; (b) symmetric increase of the distance between acetylacetonate fragment and Ir atom followed by $\mathrm{H}$ joining and acetylacetone desorption from iron surface; and (c) cleavage of one of Ir-O bonds similarly to the case of the gas phase decomposition (Figure 7). Binding energies $E_{b}$ were calculated according to the equation:

$$
E_{b}=E_{\text {hybrid }}-E_{F e}-E_{\text {complex }},
$$

where $E_{\text {hybrid }}$ is the total energy of the corresponding structure, $E_{F e}$ and $E_{\text {complex }}$ are the iron slab and isolated complex molecule total energies.
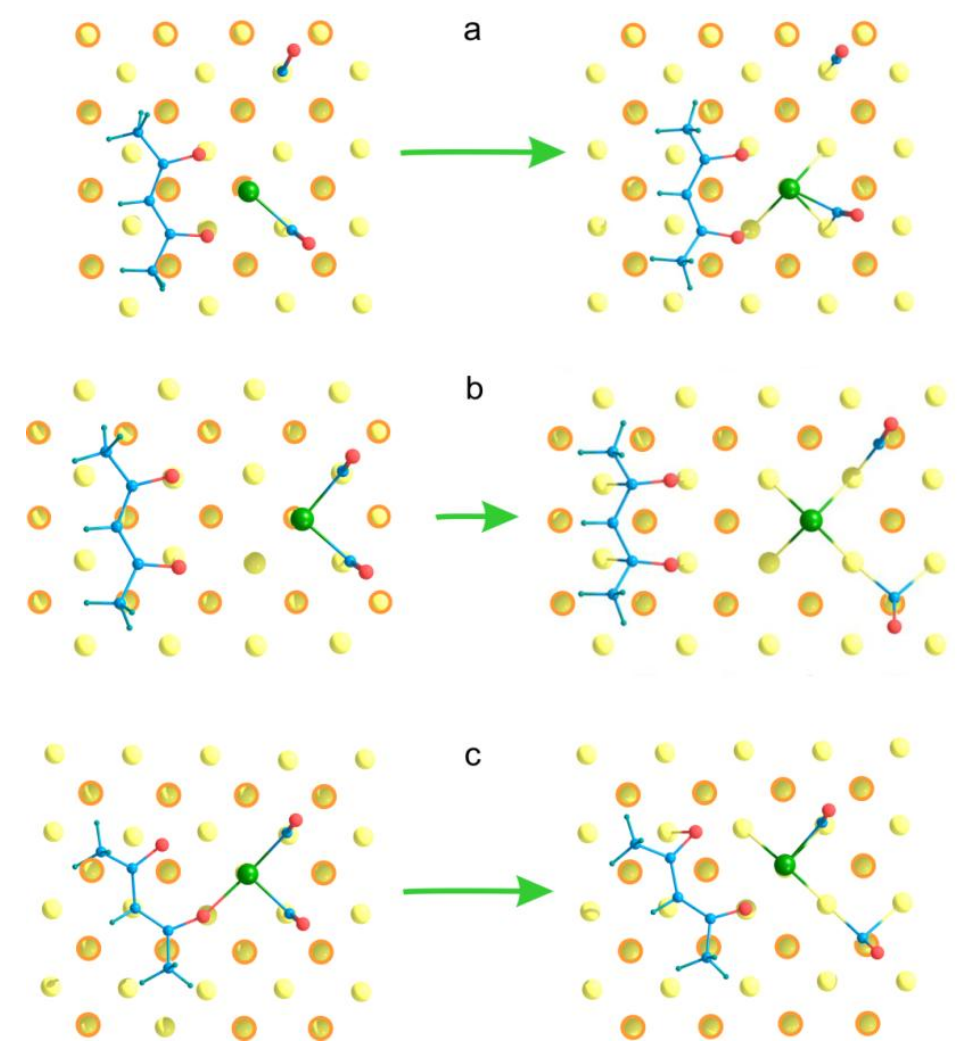

Figure 7. Possible ways of $\operatorname{Ir}(\mathrm{acac})(\mathrm{CO})_{2}$ decomposition of the $\mathrm{Fe}(001)$ surface

According to the calculated values of binding energies, the path (c) is unlikely to take place since the optimized structure is less favorable than the initially adsorbed complex. Even though the path (b) leads to the complete decomposition of the molecule; non-symmetric CO elimination is notably more energetically favorable and was used for minimum energy path calculation using NEB [37,38] method (see Table 1). It is worth mentioning that even for the least favorable path (c), the elimination of one $\mathrm{CO}$ group can be observed, and even for more symmetrical 
structure (b) two CO groups are non-equivalent in terms of distances and angles between them and surface plane.

The minimum energy path calculation was performed for the path (a) using nudged elastic band method (NEB). No potential barrier was found for the reaction of $\operatorname{Ir}(\mathrm{acac})(\mathrm{CO})_{2}$ decomposition on iron surface testifying its spontaneous nature. The previously defined symmetric structure of the adsorbed $\operatorname{Ir}($ acac $)(\mathrm{CO})_{2}$ (see Figure 5) was established to be metastable and much less favorable than those with non-symmetric positions of CO groups. Even a small displacement at the first NEB image leads to a significant gain in energy (see Table 1), which is in agreement with our previous observations. Ir-C bond distances were defined to be 2.06 and $2.77 \AA$, respectively, and $\mathrm{Ir}-\mathrm{C}-\mathrm{O}$ angles are $116.0^{\circ}$ and $126.7^{\circ}$. Thus, CO fragment starts moving from its initial position without any obstacles immediately after the adsorption and migrates along the substrate. Then $\mathrm{CO}$ adsorbs on the iron surface elsewhere and its desorption is detected with temperature increasing, which is in agreement with the previously reported data on CO adsorption and migration on the iron surface [39]. This is a possible explanation why no signal from CO molecules was detected in the mass spectrum below $300^{\circ} \mathrm{C}$ (Figure 2) [24].

Next, hydrogen recombination with an acac fragment should take place resulting in acetylacetone desorption as observed in the experiment (see Figure 2). However, keeping in mind the molecular orbital distribution (see Figure 6) we suppose that hydrogen atom more likely migrates than the whole complex molecule. In order to prove this suggestion, we calculated the energy of hydrogen atoms breakaway from acac fragment (see Figure 8). This energy can be estimated as:

$$
\begin{gathered}
E_{\text {break }}=E_{\text {acac }}-E_{\text {acac }-H}-E_{H}, \\
E_{H}=E_{F e+H}-E_{F e},
\end{gathered}
$$

where $E_{\text {acac }}$ is the total energy of initial acac fragment adsorbed on the iron surface, $E_{\text {acac-H }}$ and $E_{H}$ are the dehydrogenated acac fragment total energy and the corresponding energy of an isolated $\mathrm{H}$ atom adsorbed on the iron surface which, in its turn, is the difference between total energies of iron slab with $\left(E_{F e+H}\right)$ and without $\left(E_{F e}\right)$ hydrogen atom on it. 


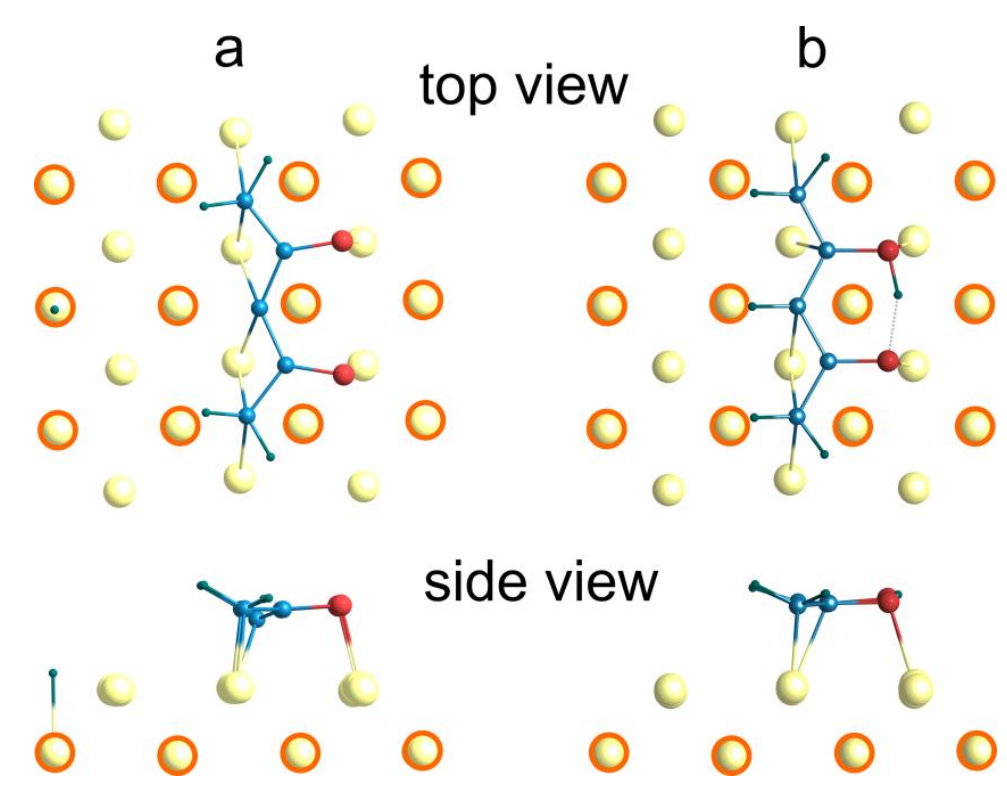

Figure 8. Hydrogen elimination from the acac fragment

According to the data reported in the literature, the preferred sites for hydrogen adsorption on iron surface depend on the $\mathrm{H}$ coverage: 4 -fold site is the more favorable the more coverage is, while 2 -fold site is more preferable at low coverage values [40]. We have checked both possible adsorption sites in order to estimate the energy of $\mathrm{H}$ breakaway from the acac fragment and found 2 -fold site to be more likely to occur. As additional test, a binding energy of hydrogen with smaller slab of iron (which corresponds to the higher hydrogen coverage) was calculated, giving an agreement with the previously reported energy value (see Table 2) [40]. Thus, 2-fold site was used for energy difference calculation. Two cases were considered (see Figure 8): (1) - one of methyl group hydrogen atoms migrates to the oxygen atom, forming hydrogen bond with the second oxygen while another methyl group hydrogen atom moves along the surface elsewhere $(0.35 \mathrm{eV}$ gain in energy); (2) - simultaneous detachment of $-\mathrm{CH}-$ and two $-\mathrm{CH}_{3}$ hydrogen atoms adsorbing on the surface without forming bonds with oxygen (5.21 eV energy gain). Hence, we have proved that acac fragment decomposition by hydrogen breakaway is more favorable. It is not reasonable to consider other possible paths of this process since this is not the main target of the present study. However, our results and the previously reported data on hydrogen migration on Fe(001) surface support our suggestions: hydrogens from one acac fragment can easily reach the other ones and then desorb in the form of acetylacetone molecule. 
Hence, according to our modeling, $\operatorname{Ir}($ acac $)(\mathrm{CO})_{2}$ decomposition process includes the following steps (see Figure 9):

1) adsorption of $\operatorname{Ir}(\mathrm{acac})(\mathrm{CO})_{2}$ on the iron surface;

2) elimination of $\mathrm{CO}$ group and its adsorption on the substrate;

3) hydrogen atom elimination and attachment by another acac fragment;

4) acetylacetone desorption;

5) $\mathrm{CO}$ desorption with the temperature increase;

6) formation of Ir nanoparticles on the iron surface.

Table 1. Binding energies for the iridium complex fragments adsorbed on $\mathrm{Fe}(001)$ surface, eV

\begin{tabular}{|l|l|}
\hline Structure & Binding energy, eV \\
\hline Initial adsorbed complex (Fig. 5) & -5.82 \\
\hline Symmetrical decomposition (Fig. 7a) & -6.01 \\
\hline Non-symmetrical decomposition by CO elimination (Fig. 7b) & -8.63 \\
\hline $\begin{array}{l}\text { Non-symmetrical decomposition by acac fragment } \\
\text { elimination (Fig. 7c) }\end{array}$ & -4.65 \\
\hline Distorted structure of initial adsorbed complex & $-8.28^{*}$ \\
\hline
\end{tabular}

*from NEB calculation

Table 2. Energies of hydrogen adsorption on Fe(001) surface, eV

\begin{tabular}{|l|l|l|}
\hline Adsorption site & This work & Reference [40] \\
\hline 4 -fold & 1.00 & \\
\hline 2 -fold & -7.04 & \\
\hline 2 -fold (higher H coverage, $\theta=0.25)^{*}$ & -2.78 & -2.64 \\
\hline
\end{tabular}

*additional test to prove the compatibility with the previously published results 


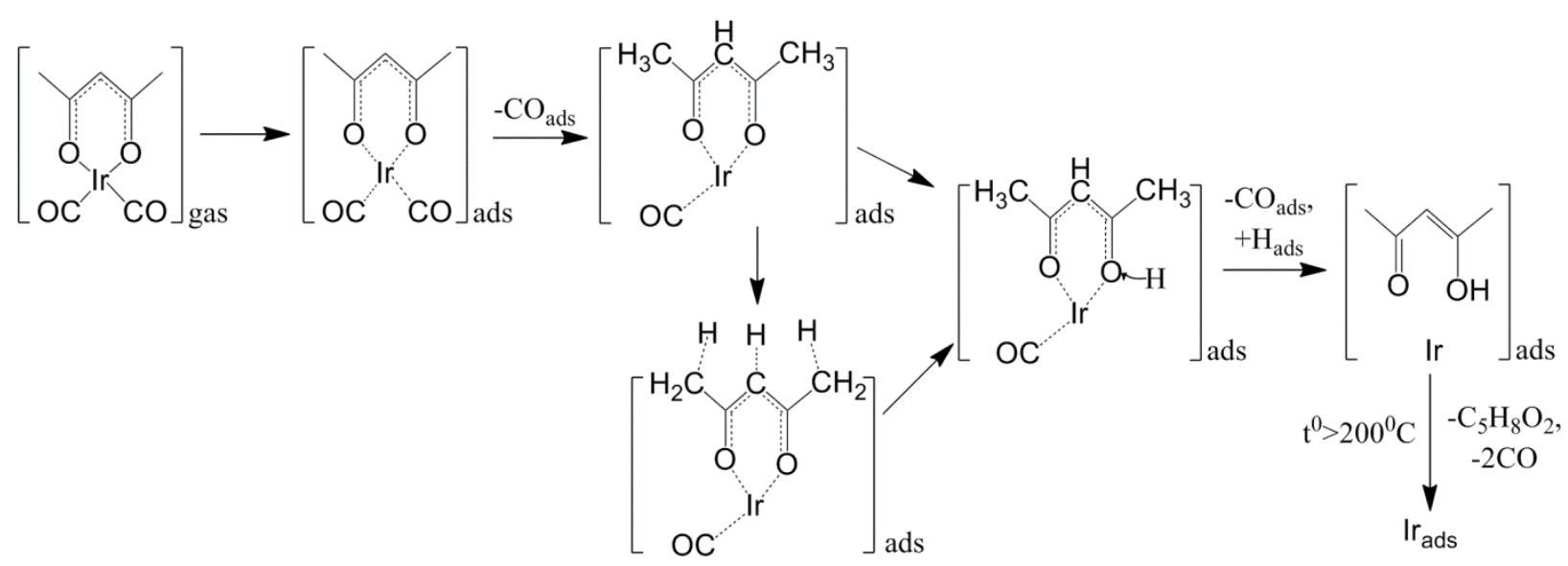

Figure 9. Scheme of $\operatorname{Ir}(\mathrm{acac})(\mathrm{CO})_{2}$ thermal destruction based on the results of quantum chemical calculations

\section{Conclusions}

In summary, the mechanism of $\operatorname{Ir}(\mathrm{acac})(\mathrm{CO})_{2}$ thermal decomposition on the iron surface as well as in the gas phase was studied by means of in situ mass spectrometry and density functional theory. Reaction taking place on the iron substrate adopts the path significantly different from that in the gas phase. The adsorption leads to strong structural distortions of the complex molecule which facilitates the following elimination of $\mathrm{CO}$ and acac fragments and their desorption with the temperature increase.

\section{Acknowledgements}

The authors would like to thank Joint Supercomputer Center of RAS, Moscow; Center of Equipment for Joint Use of Siberian Federal University, Krasnoyarsk; and Information Technology Centre, Novosibirsk State University for providing the access to their supercomputers. E.S. Vikulova is grateful to the Council on the Grants from the President of the Russian Federation (SP$3215.2016 .4)$.

\section{References}

[1] W. Wu, Z. Chen, X. Cong, L. Wang, Review on High-Temperature Oxidation-Resistant Iridium Coating for Refractory Metals, Rare Met. Mater. Eng. 42 (2013) 435-440.

[2] L.A. Geddes, R. Roeder, Criteria for the Selection of Materials for Implanted Electrodes, Ann. Biomed. Eng. 31 (2003) 879-890. doi:10.1114/1.1581292.

[3] S.F. Cogan, Neural Stimulation and Recording Electrodes, Annu. Rev. Biomed. Eng. 10 (2008) 
275-309. doi:10.1146/annurev.bioeng.10.061807.160518.

[4] V.K. Khanna, Cardiac Pacemakers, in: Implant. Med. Electron., Springer International Publishing, Cham, 2016: pp. 267-292. doi:10.1007/978-3-319-25448-7_14.

[5] J.H. Lee, H.S. Kim, J.H. Kim, S.-H. Lee, Soft implantable microelectrodes for future medicine: prosthetics, neural signal recording and neuromodulation, Lab Chip. 16 (2016) 959-976. doi:10.1039/C5LC00842E.

[6] C.R.K. Rao, D.C. Trivedi, Chemical and electrochemical depositions of platinum group metals and their applications, Coord. Chem. Rev. 249 (2005) 613-631. doi:10.1016/j.ccr.2004.08.015.

[7] A. Petrossians, J.J. Whalen III, J.D. Weiland, F. Mansfeld, Electrodeposition and Characterization of Thin-Film Platinum-Iridium Alloys for Biological Interfaces, J. Electrochem. Soc. 158 (2011) D269-D276. doi:10.1149/1.3559477.

[8] E. Slavcheva, R. Vitushinsky, W. Mokwa, U. Schnakenberg, Sputtered Iridium Oxide Films as Charge Injection Material for Functional Electrostimulation, J. Electrochem. Soc. 151 (2004) E226-E237. doi:10.1149/1.1747881.

[9] S.H. Lee, J.H. Jung, Y.M. Chae, J.-K.F. Suh, J.Y. Kang, Fabrication and characterization of implantable and flexible nerve cuff electrodes with $\mathrm{Pt}$, Ir and $\mathrm{IrOx}$ films deposited by $\mathrm{RF}$ sputtering, J. Micromechanics Microengineering. 20 (2010) 35015. doi:10.1088/0960$1317 / 20 / 3 / 035015$.

[10] D. Maurya, A. Sardarinejad, K. Alameh, Recent Developments in R.F. Magnetron Sputtered Thin Films for pH Sensing Applications-An Overview, Coatings. 4 (2014) 756-771. doi:10.3390/coatings4040756.

[11] J.R.V. Garcia, T. Goto, Chemical Vapor Deposition of Iridium, Platinum, Rhodium and Palladium, Mater. Trans. 44 (2003) 1717-1728. doi:10.2320/matertrans.44.1717.

[12] V.Y. Vasilyev, N.B. Morozova, T. V. Basova, I.K. Igumenov, a. Hassan, Chemical vapour deposition of Ir-based coatings: chemistry, processes and applications, RSC Adv. 5 (2015) 32034-32063. doi:10.1039/C5RA03566J.

[13] P. Semyannikov, V. Grankin, I. Igumenov, A. Bykov, Mechanism of Thermal Decomposition of Palladium B-Diketonates Vapour on Hot surface, J. Phys. IV Colloq. (1995) 205-211. doi:10.1051/jphyscol:1995523>.

[14] P.P. Semyannikov, I.K. Igumenov, S. V. Trubin, I.P. Asanov, In situ mass spectrometry during thermal CVD of the tris-acetylacetonates of 3-d transition metals, Le J. Phys. IV. 11 (2001) Pr3-995-Pr3-1003. doi:10.1051/jp4:20013125.

[15] V.G. Bessergenev, I.V. Khmelinskii, R.J.F. Pereira, V.V. Krisuk, A.E. Turgambaeva, I.K. Igumenov, Preparation of TiO2 films by CVD method and its electrical, structural and optical properties, Vacuum. 64 (2002) 275-279. doi:10.1016/S0042-207X(01)00318-9.

[16] J. Niinistö, A. Rahtu, M. Putkonen, M. Ritala, M. Leskelä, L. Niinistö, In Situ Quadrupole Mass Spectrometry Study of Atomic-Layer Deposition of $\mathrm{ZrO}_{2} \mathrm{Using}_{\mathrm{Cp}} \mathrm{Zr}_{\mathrm{CH}} \mathrm{CH}_{2}$ and Water, Langmuir. 21 (2005) 7321-7325. doi:10.1021/la0500732.

[17] A.Y. Kovalgin, F. Chabert-Rocabois, M.L. Hitchman, S.H. Shamlian, S.E. Alexandrov, A study by In Situ FTIR Spectroscopy of the Decomposition of Precursors for the MOCVD of High 
Temperature Superconductors, Le J. Phys. IV. 5 (1995) C5-357-C5-364.

doi:10.1051/jphyscol:1995542.

[18] T. Nakamura, T. Nishimura, K. Tachibana, Thermal Decomposition Mechanism of a Titanium Source, Ti(MPD)(METHD)[sub 2], in MOCVD, J. Electrochem. Soc. 151 (2004) C806-C810. doi:10.1149/1.1819651.

[19] J. Kwon, M. Dai, M.D. Halls, E. Langereis, Y.J. Chabal, R.G. Gordon, In Situ Infrared Characterization during Atomic Layer Deposition of Lanthanum Oxide, J. Phys. Chem. C. 113 (2009) 654-660. doi:10.1021/jp806027m.

[20] T. Hatanpää, M. Ritala, M. Leskelä, Precursors as enablers of ALD technology: Contributions from University of Helsinki, Coord. Chem. Rev. 257 (2013) 3297-3322. doi:10.1016/j.ccr.2013.07.002.

[21] E.S. Vikulova, I.Y. Ilyin, K.I. Karakovskaya, D.A. Piryazev, N.B. Morozova, Crystal structure and thermal properties of (1,1,1,5,5,5-hexafluoropentanoato-4) ·(dicarbonyl)iridium(I), J. Struct. Chem. 56 (2015) 1212-1214. doi:10.1134/S0022476615060335.

[22] E.S. Vikulova, I.Y. Ilyin, K.I. Karakovskaya, D.A. Piryazev, A.E. Turgambaeva, N.B. Morozova, Volatile iridium(I) complexes with B-diketones and cyclooctadiene: syntheses, structures and thermal properties, J. Coord. Chem. 69 (2016) 2281-2290. doi:10.1080/00958972.2016.1198955.

[23] X. Yan, T. Ai, X. Su, Z. Wang, G. Sun, P. Zhao, Synthesis and Thermal Decomposition Mechanism Study of a Novel Iridium Precursor, MATEC Web Conf. 43 (2016) 1002. doi:10.1051/matecconf/20164301002.

[24] N. V. Gelfond, N.B. Morozova, P.P. Semyannikov, S. V. Trubin, I.K. Igumenov, A.K. Gutakovskii, A. V. Latyshev, Preparation of thin films of platinum group metals by pulsed MOCVD. I. Deposition of Ir layers, J. Struct. Chem. 53 (2012) 715-724. doi:10.1134/S0022476612040142.

[25] N. V. Gelfond, P.P. Semyannikov, S. V. Trubin, N.B. Morozova, I.K. Igumenov, Deposition of Ir Nanostructured Thin Films by Pulse CVD, in: ECS Trans., ECS, 2009: pp. 871-874. doi:10.1149/1.3207679.

[26] N.B. Morozova, N.V. Gelfond, P.P. Semyannikov, S.V. Trubin, I.K. Igumenov, L. GimenoFabra, Thermal Properties of Ir(I) Precursors: Acetylacetonato(1,5-Cyclooctadiene)Iridium(I) and (Methylcyclopentadienyl)(1,5-Cyclooctadiene)Iridium(I), in: M. Allendorf, F. Maury, F. Teyssandier (Eds.), Proc. Int. Symp. Chem. Vap. Depos. XVI EUROCVD 14, 2003: pp. 120 127.

[27] P.P. Semyannikov, N.B. Morozova, K. V. Zherikova, S. V. Trubin, I.K. Igumenov, N. V. Gelfond, Preparation of Iridium Thin Film by Pulse CVD from Ir(acac)(CO), in: ECS Trans., ECS, 2009: pp. 887-892. doi:10.1149/1.3207682.

[28] N.B. Morozova, P.P. Semyannikov, S. V. Trubin, P.P. Stabnikov, A.A. Bessonov, K. V. Zherikova, I.K. Igumenov, Vapor pressure of some volatile iridium(I) compounds with carbonyl, acetylacetonate and cyclopentadienyl ligands, J. Therm. Anal. Calorim. 96 (2009) 261-266. doi:10.1007/s10973-008-9551-8. 
[29] M.A. Bespyatov, T.M. Kuzin, V.N. Naumov, E.S. Vikulova, I.Y. Ilyin, N.B. Morozova, N.V. Gelfond, Low-temperature heat capacity of $\operatorname{Ir}(\mathrm{C} 5 \mathrm{H} 7 \mathrm{O} 2)(\mathrm{C} 8 \mathrm{H} 12)$, J. Chem. Thermodyn. 99 (2016) 70-74. doi:10.1016/j.jct.2016.03.044.

[30] F. Neese, The ORCA program system, Wiley Interdiscip. Rev. Comput. Mol. Sci. 2 (2012) 7378. doi:10.1002/wcms.81.

[31] K. V. Zherikova, N. V. Kuratieva, N.B. Morozova, Crystal structure of (acetylacetonato) (dicarbonyl)iridium(I), J. Struct. Chem. 50 (2009) 574-576. doi:10.1007/s10947-009-0088-x.

[32] M. Karabacak, M. Kurt, Comparison of experimental and density functional study on the molecular structure, infrared and Raman spectra and vibrational assignments of 6chloronicotinic acid, Spectrochim. Acta Part A Mol. Biomol. Spectrosc. 71 (2008) 876-883. doi:10.1016/j.saa.2008.02.014.

[33] I. Morrison, D.M. Bylander, L. Kleinman, Nonlocal Hermitian norm-conserving Vanderbilt pseudopotential, Phys. Rev. B. 47 (1993) 6728-6731. doi:10.1103/PhysRevB.47.6728.

[34] J.P. Perdew, J.A. Chevary, S.H. Vosko, K.A. Jackson, M.R. Pederson, D.J. Singh, C. Fiolhais, Atoms, molecules, solids, and surfaces: Applications of the generalized gradient approximation for exchange and correlation, Phys. Rev. B. 46 (1992) 6671-6687. doi:10.1103/PhysRevB.46.6671.

[35] J.P. Perdew, J.A. Chevary, S.H. Vosko, K.A. Jackson, M.R. Pederson, D.J. Singh, C. Fiolhais, Erratum: Atoms, molecules, solids, and surfaces: Applications of the generalized gradient approximation for exchange and correlation, Phys. Rev. B. 48 (1993) 4978-4978. doi:10.1103/PhysRevB.48.4978.2.

[36] H.J. Monkhorst, J.D. Pack, Special points for Brillouin-zone integrations, Phys. Rev. B. 13 (1976) 5188-5192. doi:10.1103/PhysRevB.13.5188.

[37] G. Henkelman, B.P. Uberuaga, H. Jónsson, A climbing image nudged elastic band method for finding saddle points and minimum energy paths, J. Chem. Phys. 113 (2000) 9901-9904. doi:10.1063/1.1329672.

[38] G. Henkelman, H. Jónsson, Improved tangent estimate in the nudged elastic band method for finding minimum energy paths and saddle points, J. Chem. Phys. 113 (2000) 9978-9985. doi:10.1063/1.1323224.

[39] D.C. Sorescu, D.L. Thompson, M.M. Hurley, C.F. Chabalowski, First-principles calculations of the adsorption, diffusion, and dissociation of a CO molecule on the Fe(100) surface, Phys. Rev. B. 66 (2002) 35416. doi:10.1103/PhysRevB.66.035416.

[40] D.C. Sorescu, First principles calculations of the adsorption and diffusion of hydrogen on Fe(100) surface and in the bulk, Catal. Today. 105 (2005) 44-65.

doi:10.1016/j.cattod.2005.04.010. 